\title{
INTRASPECIFIC VARIATION IN A PREDATOR AFFECTS COMMUNITY STRUCTURE AND CASCADING TROPHIC INTERACTIONS
}

\author{
David M. Post,${ }^{1,4}$ Eric P. Palkovacs,,${ }^{1,3}$ Erika G. Schielke, ${ }^{1}$ and Stanley I. Dodson ${ }^{2}$ \\ ${ }^{1}$ Department of Ecology and Evolutionary Biology, Yale University, New Haven, Connecticut 06520-8106 USA \\ ${ }^{2}$ Department of Zoology, University of Wisconsin, Madison, Wisconsin 53706 USA
}

\begin{abstract}
Intraspecific phenotypic variation in ecologically important traits is widespread and important for evolutionary processes, but its effects on community and ecosystem processes are poorly understood. We use life history differences among populations of alewives, Alosa pseudoharengus, to test the effects of intraspecific phenotypic variation in a predator on pelagic zooplankton community structure and the strength of cascading trophic interactions. We focus on the effects of differences in (1) the duration of residence in fresh water (either seasonal or year-round) and (2) differences in foraging morphology, both of which may strongly influence interactions between alewives and their prey. We measured zooplankton community structure, algal biomass, and spring total phosphorus in lakes that contained landlocked, anadromous, or no alewives. Both the duration of residence and the intraspecific variation in foraging morphology strongly influenced zooplankton community structure. Lakes with landlocked alewives had small-bodied zooplankton year-round, and lakes with no alewives had large-bodied zooplankton year-round. In contrast, zooplankton communities in lakes with anadromous alewives cycled between large-bodied zooplankton in the winter and spring and small-bodied zooplankton in the summer. In summer, differences in feeding morphology of alewives caused zooplankton biomass to be lower and body size to be smaller in lakes with anadromous alewives than in lakes with landlocked alewives. Furthermore, intraspecific variation altered the strength of the trophic cascade caused by alewives. Our results demonstrate that intraspecific phenotypic variation of predators can regulate community structure and ecosystem processes by modifying the form and strength of complex trophic interactions.
\end{abstract}

Key words: alewife; Alosa pseudoharengus; interspecific variation; intraspecific variation; keystone species; life history differences; predator identity; size-selective predation; trophic cascade; zooplankton.

\section{INTRODUCTION}

Ecologists have long explored the implications of interspecific variation for ecological interactions, and it is now clear that species identity and the incidence of important species (e.g., dominant species, keystone species, foundation species, or ecosystem engineers) strongly shape community structure and regulate ecosystem function (e.g., Brooks and Dodson 1965, Paine 1966, Carpenter et al. 1987, Jones et al. 1994, Schmitz and Suttle 2001, Whitham et al. 2006). For example, Brooks and Dodson (1965) and Paine (1966) made clear the importance of predators in controlling community structure, and together with Hairston et al. (1960), triggered decades of work on complex trophic interactions in diverse ecosystems (Estes and Palmisan 1974, Oksanen et al. 1981, Carpenter et al. 1987, Pace et al. 1999, Schmitz et al. 2000). This research typically has assumed that the mean effect of a species is sufficient to

Manuscript received 25 July 2007; revised 15 November 2007; accepted 27 November 2007. Corresponding Editor: P. R. Leavitt.

${ }^{3}$ Present address: School of Biology and Ecology, University of Maine, Orono, Maine 04469-5751 USA.

${ }^{4}$ E-mail: david.post@yale.edu characterize trophic interactions and consequently, has often overlooked or obscured the potential effects of intraspecific variation in ecologically important traits. Intraspecific variation is widely studied because of its implications for adaptive phenotypic differentiation (Reznick et al. 1997, Reznick and Ghalambor 2001, Reznick et al. 2001) and ecological speciation (Dieckmann and Doebeli 1999, Schluter 2001, Doebeli and Dieckmann 2003, Rundle and Nosil 2005). While intraspecific variation can influence the form and strength of ecological interactions (Thompson 1988, Menge et al. 1994, Abrams and Matsuda 1997, Thompson 1998, Wimp et al. 2004, Whitham et al. 2006), few studies have addressed the effects of intraspecific variation on community structure and ecosystem function (Treseder and Vitousek 2001, Johnson and Agrawal 2005, Wimp et al. 2005).

Here we use differences in life history among populations of alewives, Alosa pseudoharengus, to test the effects of intraspecific phenotypic variation on pelagic zooplankton community structure and the strength of cascading trophic interaction. We test the effects of the incidence of and intraspecific variation among alewife populations by sampling lakes in coastal New England that contain (1) no alewives, (2) land- 
locked alewives that spend their entire life in freshwater ecosystems, or (3) anadromous alewives that move between freshwater and marine habitats. Landlocked alewives are considered both an archetypal size-selective predator (Brooks and Dodson 1965) and a putative keystone species (Power et al. 1996), and therefore, phenotypic differences between anadromous and landlocked populations could strongly affect the ecological role of alewives in lakes. Landlocked alewives are known to structure zooplankton communities and regulate water quality in lakes across eastern North America (Brooks and Dodson 1965, Wells 1970, Eck and Wells 1987, Harman and Albright 2002, Madenjian et al. 2002, Mills et al. 2003), but little is known about the ecological role of anadromous alewives (but see Vigerstad and Cobb 1978, Gregory et al. 1983). The transition from an anadromous to a landlocked life history can produce considerable intraspecific variation (Hendry et al. 2004) that may strongly affect the ecological role of alewives.

Here we focus on phenotypic differences in (1) the duration of residence (either seasonal or year-round) and (2) morphological differences of alewives that can influence prey selectivity. The duration of residence can strongly influence seasonal patterns of predator-prey interactions (e.g., Post and Kitchell 1997, Post et al. 1997), and in our lakes it is mediated by differences in spatial connectivity among lakes. Lakes spatially isolated from the coastal ocean contain either landlocked or no alewives, and predation on zooplankton is likely to be intense throughout the year where landlocked alewives are present, or weak throughout the year where alewives are absent (an extrapolation of Brooks and Dodson 1965). Lakes linked to the coastal ocean are spatially open to the movement of alewives, which allows anadromous alewives to have a duration of lake residence of less than one year. In our lakes, adult alewives typically do not feed in fresh water, but youngof-the-year anadromous alewives are present and of sufficiently large body size to prey upon large zooplankton $(>0.5 \mathrm{~mm})$ from June to October or November when the last individuals migrate to the ocean. We predict that the intensity of zooplanktivory will vary seasonally in lakes with anadromous alewives.

Gape width and gill raker spacing are two morphological traits that influence the foraging behavior and efficiency of planktivorous fish (Mummert and Drenner 1986, Lazzaro 1987, Macneill and Brandt 1990, Graeb et al. 2005). Anadromous alewives have larger gape and wider gill raker spacing than landlocked alewives (Palkovacs 2007, Palkovacs et al. 2008; see Plate 1). Except for early summer when they are gape limited, anadromous alewives are positively size selective and prey upon the largest available zooplankton in the lake. In contrast, landlocked alewives are neutrally size selective and tend to prey upon the average-sized zooplankton throughout the summer (Palkovacs 2007). These differences in morphology and prey selectivity should modify the functional form of interactions between alewives and their zooplankton prey, particularly in summer when anadromous and landlocked alewives are at maximum biomass in fresh water and transient spring dynamics have ended.

Here we ask how differences in the duration of residence and feeding morphology modify the role of anadromous and landlocked alewives as size-selective predators. We compared isolated lakes with and without landlocked alewives to test the effects of the incidence of alewives, and we compared landlocked and anadromous alewife lakes to test the effects of intraspecific differences in the duration of residence and feeding morphology. Like Brooks and Dodson (1965), we focused on zooplankton community structure (biomass and size structure), but in addition, we sampled phytoplankton and nutrient concentrations (e.g., Carpenter et al. 2001) to test the effects of intraspecific phenotypic differences on trophic cascades in lakes. In lakes with landlocked alewives (landlocked lakes), we expected to find zooplankton communities dominated by small-bodied zooplankton throughout the year. In lakes with no alewives (no-alewife lakes), we expected to find zooplankton communities dominated by large-bodied zooplankton throughout the year. In lakes with anadromous alewives (anadromous lakes), we expected to find large-bodied zooplankton in the spring, when young-of-the-year (YOY) anadromous alewives are not yet large enough to prey upon large-bodied zooplankton, and we expected to find small-bodied zooplankton communities in the summer, after YOY anadromous alewives reach a body size sufficiently large to prey upon the largest zooplankton. We also expected that the larger gape and positive size selectivity of anadromous alewives would result in smaller size and lower biomass of zooplankton in midsummer than that found in landlocked lakes. Finally, we expected that intraspecific variation would alter the strength of cascading trophic interactions such that lakes with no alewives would have lower algal biomass per unit of spring total phosphorus than landlocked lakes, and that landlocked lakes would have lower algal biomass per unit of spring total phosphorous than anadromous lakes.

\section{Methods}

Alewife life history.-Anadromous alewives were historically abundant along the Atlantic coast of North America from Labrador to the Carolinas and are one of the oldest documented fisheries in North America (Scott and Crossman 1973), but most populations have been in decline for the past 40-50 years. Alewives are now a species of management concern across their native range (Atlantic States Marine Fisheries Commission [ASMFC] 1999). Anadromous alewives generally spawn in coastal lakes and ponds where young-of-the-year (YOY) spend their first summer of life. YOY anadromous alewives migrate to the ocean in the fall, grow to a mature size in three to four years, and return to fresh water each spring thereafter to spawn. Alewives may become naturally 
landlocked, as do populations of many other anadromous fish species (McDowall 1988), but some populations found in coastal New England watersheds were established by intentional human introductions (Phillips et al. 1987). Compared to anadromous populations, landlocked alewives exhibit slower growth, earlier age at maturity (two to three years vs. three to four years), and smaller size at maturity $(100-150 \mathrm{~mm}$ vs. $250-300 \mathrm{~mm}$; Graham 1956). In accordance with their smaller body size, landlocked females have reduced fecundity (Scott and Crossman 1973). In Connecticut, anadromous alewives spawn three to six weeks earlier than landlocked alewives.

The origin of morphological variation among alewife populations in our study lakes is of central importance to interpreting our results. We have not assessed the heritability of gape and gill raker spacing in alewives, but these foraging traits are highly heritable (Day et al. 1994, Foote et al. 1999, Funk et al. 2005) and respond rapidly to selection in many fish species (Nursall 1974, Schluter and McPhail 1992). In our populations, differences in gape width and gill raker spacing were maintained when anadromous and landlocked alewives were raised in common garden mesocosm experiments for two months, suggesting that morphological differences have an important genetic component (Appendix A). Population genetic analyses (mtDNA and microsatellite markers) indicate that our anadromous alewife populations are exchanging genes, while our landlocked populations are genetically isolated (Palkovacs et al. 2008). These results support a phylogenetic raceme model of divergence (Bell and Foster 1994) for most landlocked populations, where anadromous populations form an ancestral core from which (unstocked) landlocked populations have diverged independently (Table 1). This divergence may have occurred as recently as about 270 years (180 generations) before the present, during the time of colonial dam building in New England (Palkovacs et al. 2008). Divergence time estimates, the pattern of divergence, and results from the common garden mesocosm experiments all support the conclusion that differences in foraging traits result from parallel evolution of morphological traits resulting from the transition from anadromy to freshwater residency (Palkovacs 2007, Palkovacs et al. 2008).

Study sites.-We sampled 19 lakes in Connecticut (Fig. 1) reflecting two levels of spatial openness and three different food web configurations: lakes isolated from the coastal ocean with landlocked alewives or without alewives, and lakes connected to the coastal ocean with anadromous alewives (Table 1). Many of the spatially isolated lakes were isolated from the coastal ocean by dams (either at the lake outlet or downstream of the lake) while others, located higher in the landscape, were never connected to the coastal ocean at recent ecological time scales. We returned to most of the landlocked and no-alewife lakes originally sampled by Brooks and Dodson (1965), although some of these
TABLE 1. Study lakes, basic lake characteristics, and the origin of landlocked populations of alewives, Alosa pseudoharengus, in Connecticut, USA.

\begin{tabular}{|c|c|c|c|c|}
\hline Lake name & Lake type & $\begin{array}{c}\text { Area } \\
\text { (ha) }\end{array}$ & $\begin{array}{c}\text { Max. } \\
\text { depth (m) }\end{array}$ & $\begin{array}{c}\mathrm{TP} \dagger \\
(\mu \mathrm{g} / \mathrm{L})\end{array}$ \\
\hline Bride $\$$ & anadromous & 18.2 & 10.7 & 15.5 \\
\hline Dodget & anadromous & 13.9 & 15.5 & 24.5 \\
\hline Gorton & anadromous & 21.5 & 3.4 & 19.8 \\
\hline Amos & landlocked§̧ & 42.0 & 13.7 & 41.8 \\
\hline Avery & landlocked\$ & 20.5 & 3.4 & 36.1 \\
\hline Beach & landlocked || & 157.7 & 19.2 & 7.6 \\
\hline Long & landlocked§ & 39.9 & 21.0 & 25.2 \\
\hline Pattagansett & landlocked§̧ & 49.2 & 10.1 & 17.3 \\
\hline Quonnipaug & landlocked§ & 44.6 & 14.5 & 47.1 \\
\hline Rogers: & landlocked§ & 106.0 & 20.0 & 14.9 \\
\hline Uncas & landlocked || & 27.6 & 11.9 & 18.1 \\
\hline Bashan & no-alewife & 110.5 & 14.3 & 9.7 \\
\hline Besek & no-alewife & 47.8 & 7.9 & 65.8 \\
\hline Black & no-alewife & 30.2 & 7.0 & 68.6 \\
\hline Gardner & no-alewife & 194.7 & 13.4 & 23.2 \\
\hline Green Falls & no-alewife & 19.8 & 7.9 & 8.2 \\
\hline Hayward & no-alewife & 79.6 & 10.7 & 21.0 \\
\hline Linsleyt & no-alewife & 9.4 & 13.4 & 149.8 \\
\hline Wyassup & no-alewife & 37.1 & 8.2 & 13.8 \\
\hline
\end{tabular}

Notes: Data are derived from this study and from Connecticut Department of Environmental Protection surveys conducted in the 1970s, 1980s, and 1990s (Frink and Norvell 1984, Phillips et al. 1987, Jacobs and O'Donnell 2002, Palkovacs et al. 2008).

$\dagger$ Spring total phosphorus concentration $(\mu \mathrm{g} / \mathrm{L})$.

\$ Lake sampled weekly in 2004, 2005, and 2006.

$\S$ Population genetic analyses (Palkovacs et al. 2008) and stocking records (Phillips et al. 1987) indicate that landlocked populations are independently derived from anadromous ancestors.

|| Population genetic analyses (Palkovacs et al. 2008) and stocking records (Phillips et al. 1987) indicate that landlocked populations were stocked from previously landlocked populations.

lakes had changed state (e.g., Linsley Pond contained no alewives during this study). To these previously studied lakes we have added three anadromous alewife lakes. Lakes were classified as landlocked, anadromous, or noalewife lakes based on a combination of direct sampling, Connecticut Department of Environmental Protection (CT DEP) stocking records, and records from intensive CT DEP electroshocking surveys conducted between 1988 and 1995 (Jacobs and O'Donnell 2002). We have sampled adult and YOY anadromous alewives from all of the anadromous lakes and adult or YOY landlocked alewives from all of the landlocked lakes.

While there is considerable variation among our study lakes (Table 1), there are no significant differences in the area (ANOVA, $\log$ (area), $F_{2,16}=2.0, P=0.16$ ), maximum depth $\left(F_{2,16}=1.6, P=0.24\right)$ or spring total phosphorus concentrations $\left(F_{2,16}=0.91, P=0.42\right)$ among landlocked, anadromous, and no-alewife lakes. Fisheries records from the CT DEP show that our study lakes have similar fish community composition, except for large differences in the incidence of anadromous or landlocked alewives (Jacobs and O'Donnell 2002).

Sampling design and sample analyses.-We sampled all lakes in spring and summer to test for differences among lake types. Major response variables were spring 


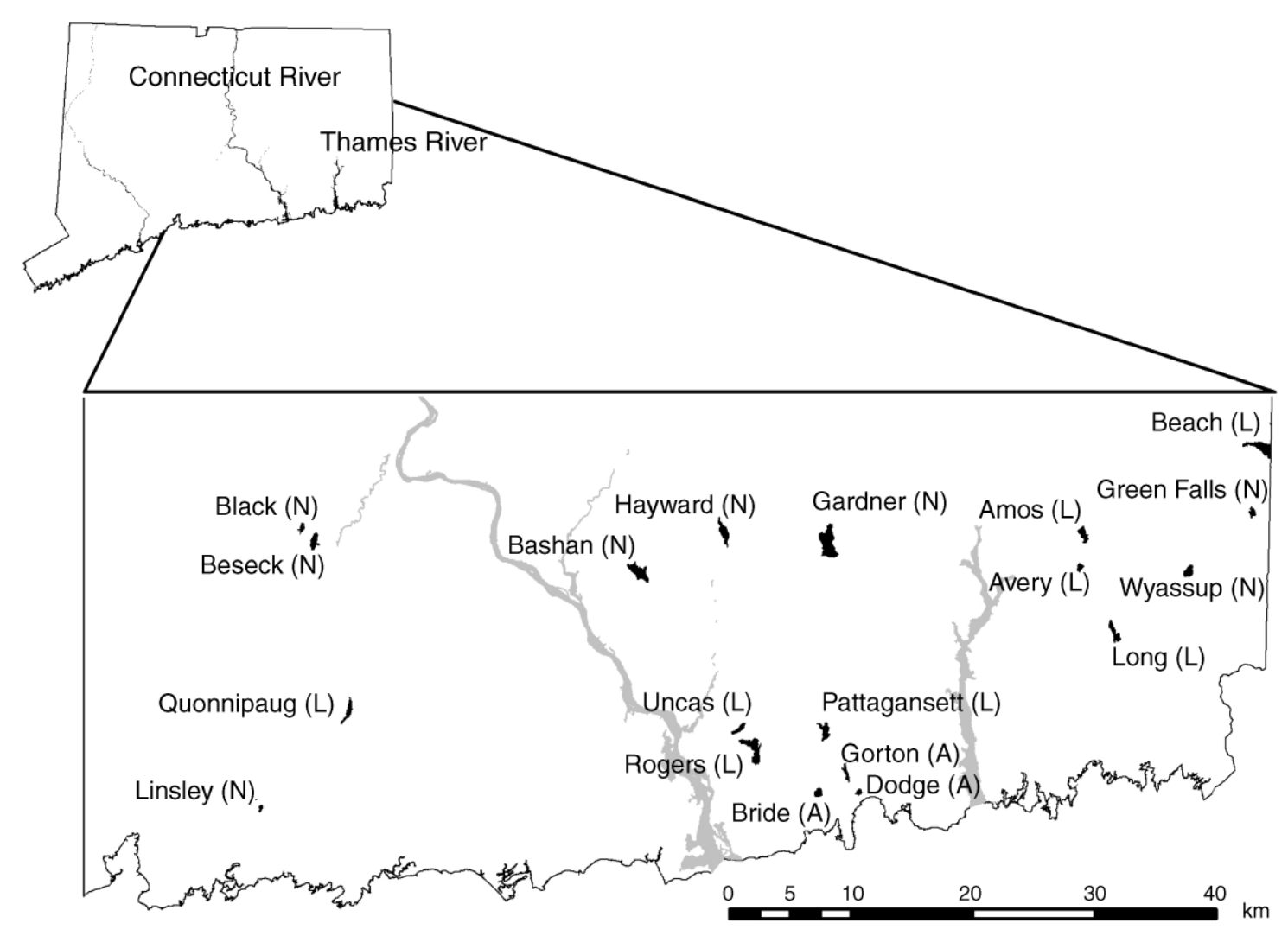

FIG. 1. Location of study lakes in Connecticut, USA. Lakes are labeled as having anadromous (A), landlocked (L), or no alewives (N), Alosa pseudoharengus.

and summer zooplankton biomass, size, and multivariate species composition, and summer algal biomass. In addition, we sampled a subset of six lakes every other week during 2004-2006 to provide a higher temporal resolution of seasonal changes in zooplankton biomass and length (Table 1). These six lakes were chosen because they are part of a long-term sampling program and whole-lake experiments. We sampled most lakes on one date in the spring (April) and twice from July to September, from which we calculated the summer mean. In the six lakes that we sampled biweekly, we estimated the spring mean from data collected in late March and April (two to three dates) and the summer mean from data collected from July to September (six to seven dates). We used spring data from 2005 for Linsley, Pattagansett, Quonnipaug, and Rogers, and spring data from 2005 and 2006 for Bride and Dodge. We used summer data from 2004 and 2005 for all six lakes. We used lake years as replicates because there were no significant autocorrelations in algal biomass, zooplankton length, or zooplankton biomass at lags longer than four weeks. Zooplankton and phytoplankton response variables are typically autocorrelated at a lag of one to two weeks and show little indication of autocorrelation among years (Carpenter and Kitchell 1993, Carpenter et al. 1996, Carpenter et al. 2001). Data from Gorton and Avery ponds were used for analyses of zooplankton size structure and community composition (relative abundances), but were excluded from analyses of biomass because their shallow depths (Table 1) made biomass estimates less reliable in comparison to other lakes.

Zooplankton were collected from the deepest basin of each lake using a $30 \mathrm{~cm}$ diameter, $90 \mathrm{~cm}$ long, $80-\mu \mathrm{m}$ mesh plankton net. Each sample was pooled from two replicate tows taken vertically through the water column and was preserved in $70 \%$ ethanol. In each lake, the depth sampled was two to three meters less than the maximum lake depth. Samples were split using a plankton splitter until there were 200-400 cladocerans and copepods in the subsample. We then enumerated the subsample to genus (Diaptomidae, some cyclopoid copepods, and Alona spp.) or species and measured the total length of either the entire sample or the first 200 individuals, whichever came first. We did not count or identify rotifers. Zooplankton dry mass was estimated from measured length and species-specific length-mass regressions following Downing and Rigler (1984).

Algal biomass was estimated from chlorophyll $a$ concentration (chl $a$ ). Samples were collected from five depths representing the top, middle, and bottom of the epilimnion, the metalimnion at the thermocline, and the hypolimnion. Here we report mean epilimnetic chlorophyll concentrations for the total phytoplankton community and for the fraction of the phytoplankton 
community $<30 \mu \mathrm{m}$, an index of edible phytoplankton biomass. Samples were filtered on to Whatman GF/F filters (Whatman, Brentford, UK) and analyzed for chl $a$ concentrations, corrected for pheopigments, on a Turner Designs TD-700 fluorometer (Turner Designs, Sunnyvale, California, USA; Marker et al. 1980) following Environmental Protection Agency (EPA) method 445.0.

Spring total phosphorus concentrations were measured in the spring of 2005 in epilimnetic samples taken within two weeks of ice out. All lakes were isothermal at sampling. Phosphorus concentrations were measured using persulfate digestion and colorimetric analysis on an Astoria 2 autoanalyzer (Astoria-Pacific International, Clackamas, Oregon, USA).

We estimated alewife biomass monthly from April to September 2005 in six of our study lakes (Bride, Dodge, Gorton, Pattagansett, Quonnipaug, and Rogers). Alewives were collected in a pelagic purse seine composed of $3.18-\mathrm{mm}$ mesh. The seine is $4.87 \mathrm{~m}$ deep and $35.36 \mathrm{~m}$ long and encircled an area of $100 \mathrm{~m}^{2}$. All fish were counted in three to five replicate net sets to provide density estimates, and a subset of fish was measured for length and mass to estimate biomass. Here we report wet biomass $\mathrm{g} / \mathrm{m}^{2}$ in July and August.

Statistical analyses.-We tested for differences in zooplankton length and biomass among the three lake types using planned contrasts. Our sampling was designed to test for differences among lake types in spring and summer, and differences within lake types between spring and summer. Within-season contrasts test for the differential effect of anadromous and landlocked alewives on zooplankton community structure, whereas between-season contrasts test whether differences in zooplankton communities are maintained throughout the growing season. Comparisons between landlocked and no-alewife lakes test the effects of the incidence (presence or absence) of alewives on food web structure, because both lake types are spatially isolated from the ocean. Comparisons between landlocked and anadromous lakes test the effects of intraspecific differences in morphology and duration of residence on food web structure. Contrasts were run on cladoceran and copepod length, large-cladoceran and largecopepod biomass (mean individual size $>0.5 \mathrm{~mm}$ ), and small-cladoceran and small-copepod biomass (mean individual size $<0.5 \mathrm{~mm}$ ). Large cladocerans included Daphnia spp., Leptodora kindtii, and Sida crystalline; small cladocerans included Alona spp., Bosmina spp., Cerodaphnia spp., Chydorus sphaericus, Diaphanosoma spp., Holopedium gibberum, and Moina micrura; small copepods included immature cyclopoid and calanoid copepods, and Tropocyclops extensus; and large copepods included Acanthocyclops spp., Cyclops spp., Diacyclops thomasi, Epichura lacustris, Eucyclops spp., Mesocyclops edax, and Microcyclops spp. Because contrasts were planned a priori, each contrast was evaluated at an alpha of 0.05 (Sokal and Rohlf 1995). Zooplankton length and biomass variables were $\log _{10^{-}}$ transformed to improve normality and homoscedasticity. All analyses were conducted in SAS (version 8.2, SAS Institute, Cary, North Carolina, USA).

We tested for differences in zooplankton community structure among the three lake types using analysis of similarity (ANOSIM). ANOSIM uses a nonparametric permutation and randomization procedure to test for significant differences between pairs of treatments (lake types) based on a matrix of similarity (Clarke 1993). We based our analysis on untransformed Euclidean distances calculated from relative species biomass and ran 999 permutations per test. The resulting R-statistic provides a measure of compositional dissimilarities between groups (lake types), with a value of 0 indicating random groupings. We included all crustacean zooplankton in our analyses, with the exceptions of copepod nauplii and species that occurred in only one sample (Moina, Acroperus, Leptodora). We examined spring and summer sampling dates independently and used nonmetric multidimensional scaling (NMDS) to visualize community differences in two dimensions. We calculated similarity percentages to identify those species contributing the most (up to $90 \%$ ) to community similarity within lake types and to community dissimilarity between lakes types. ANOSIM, NMDS, and similarity percentages were performed using the software package PRIMER 5 (Primer-E, Ivybridge, UK).

\section{Results}

Alewife morphology and biomass.-Landlocked and anadromous alewives exhibited substantial differences in feeding morphology in the summer of 2005 (Fig. 2, Plate 1). Although gape width and gill raker spacing were not significantly different in July $\left(F_{1,4}=2.03, P=0.23\right.$ for gape; $F_{1,4}=2.13, P=0.22$ for gill raker), by August anadromous populations had both larger gapes $\left(F_{1,4}=\right.$ 18.0, $P=0.01)$ and wider gill raker spacing $\left(F_{1,4}=13.8\right.$, $P=0.02$; Fig. 2a, b). In contrast, there were no significant differences in the mean length of anadromous and landlocked populations in July (ANOVA, $F_{1,4}=$ $0.18, P=0.69)$ or August $\left(F_{1,4}=5.01, P=0.09\right.$; Fig. $\left.2 \mathrm{c}\right)$, or in alewife biomass in July $\left(F_{1,4}=0.001, P=0.98\right)$ or August $\left(F_{1,4}=1.08, P=0.36\right.$; Fig. $\left.2 \mathrm{~d}\right)$.

Zooplankton size.-We observed large differences in cladoceran and copepod size between landlocked and no-alewife lakes in both spring and summer (Fig. 3). Cladocerans and copepods were significantly larger in no-alewife lakes than in landlocked lakes, and there were no significant differences in cladoceran and copepod size between spring and summer in either landlocked or noalewife lakes (Fig. 3; Appendix B). In contrast, anadromous lakes showed pronounced seasonal changes in cladoceran and copepod length. In spring, mean cladoceran and copepod lengths in anadromous lakes were lower than but not significantly different from those observed in no-alewife lakes (Fig. 3; Appendix B). The mean cladoceran and copepod lengths decreased significantly between spring and summer in anadromous 

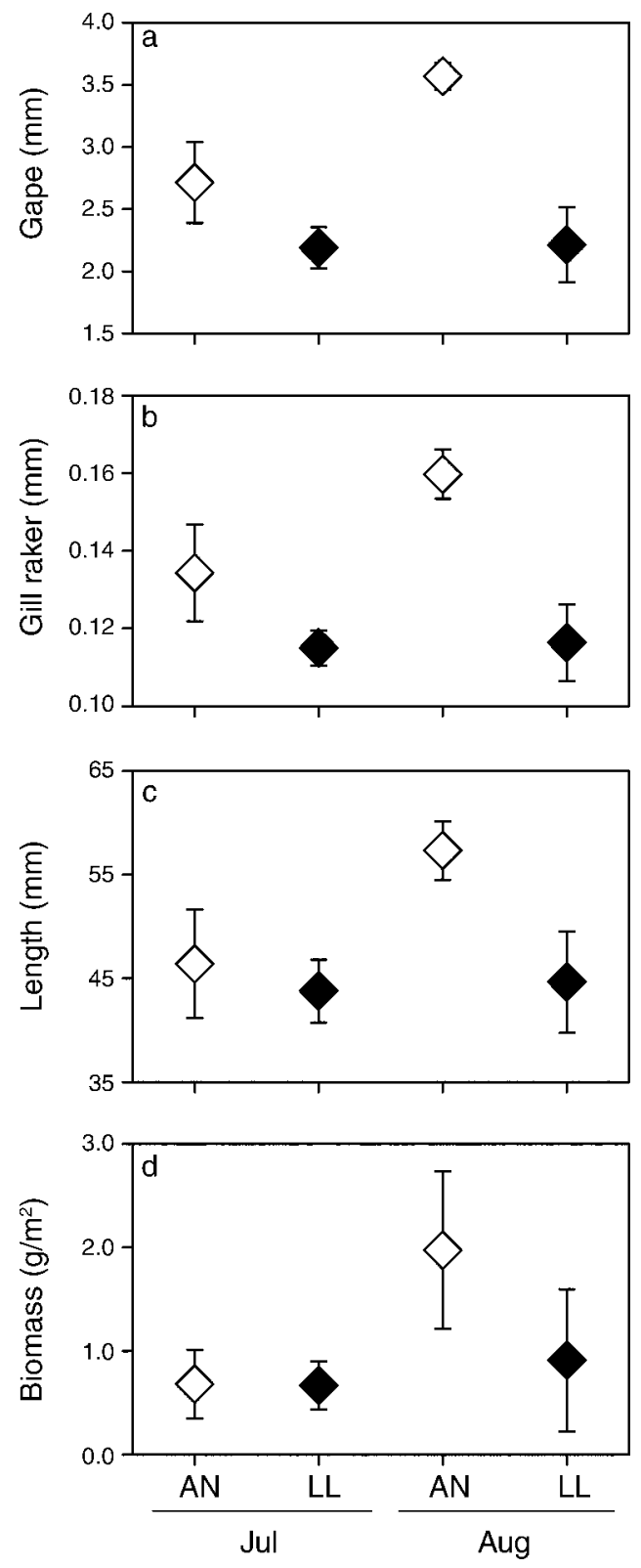

FIG. 2. Mean ( \pm SE) (a) gape width (b) gill raker spacing, (c) total length, and (d) biomass of alewives in three anadromous lakes (AN, open diamonds: Bride, Dodge, and Gorton) and three landlocked lakes (LL, solid diamonds: Pattagansett, Quonnipaug, and Rogers) in July and August 2005.

lakes. In summer, mean cladoceran and copepod lengths in anadromous lakes were significantly smaller than those found in landlocked lakes (Fig. 3; Appendix B).

Regular sampling in a subset of our lakes provided a higher temporal resolution picture of the seasonal patterns of variation in copepod and cladoceran length (Fig. 4). Landlocked lakes had uniformly low mean cladoceran length from March through November, while the no-alewife lake had high cladoceran length from March through November (Fig. 4a). In contrast, cladoceran length in anadromous lakes started out higher than that observed in landlocked lakes in April and May, but was lower than that observed in landlocked lakes from the end of June through November (Fig. 4a). Mean cladoceran length started to decline in these lakes at the end of May and continued to decline through to the end of June (Fig. 4a).

Copepod length was much more variable than cladoceran length both among lakes of the same type (especially in anadromous lakes; Fig. 3b) and seasonally in all three lake types (Fig. 4b). In general, copepod length was consistently high in the no-alewife lake from March through November (Fig. 4b). In landlocked lakes, mean copepod lengths were considerably lower than those found in no-alewife lakes from March through November, and it appears that mean copepod lengths declined in these lakes after July (Fig. 4b). In anadromous lakes, mean copepod lengths were higher than those observed in landlocked lakes in March-June and then fell to lengths similar to those observed in the landlocked lakes. The seasonal decline in copepod
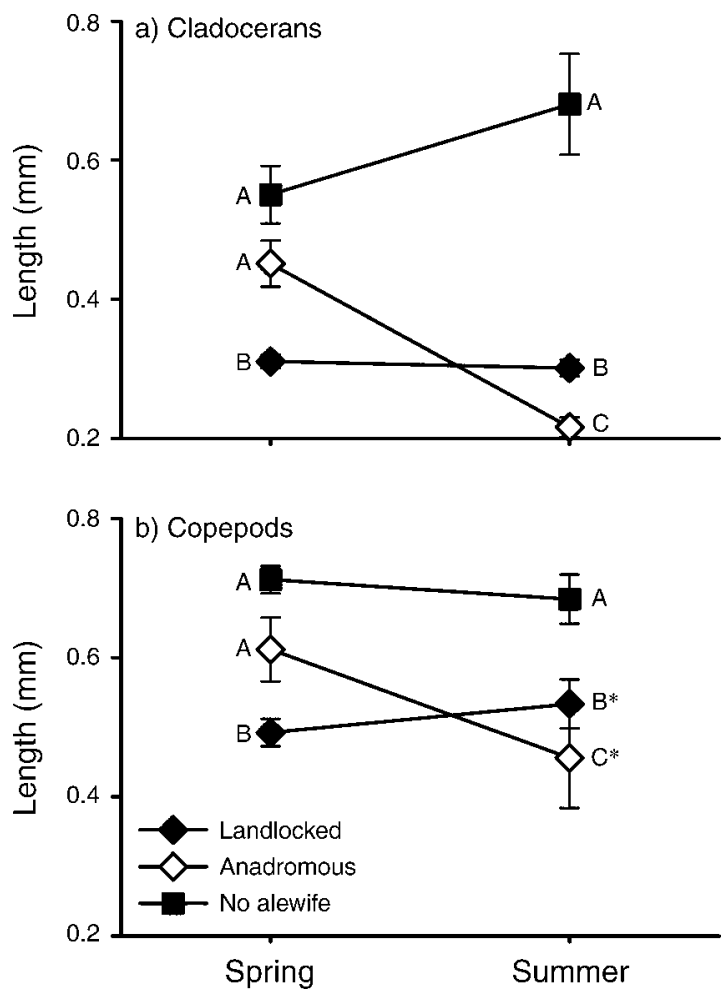

FIG. 3. Mean length $( \pm \mathrm{SE})$ of (a) cladocerans and (b) copepods in landlocked, anadromous, and no-alewife lakes in spring and summer. Different uppercase letters indicate significant differences $(P \leq 0.05)$ among lake types in spring or summer. Significant differences in cladoceran and copepod length between spring and summer were found only in anadromous alewife lakes. Asterisks indicate that the comparison between the two values had a $P$ value of 0.0503 . 
length occurred in mid-June, about two weeks later than that for cladocerans (Fig. 4).

Zooplankton biomass.-As expected, we found a higher biomass of large cladocerans and large copepods in no-alewife lakes than in landlocked lakes in both spring and summer (Fig. 5a, b; Appendix B). Although not generally significant, we also found a higher biomass of small cladocerans and small copepods in landlocked lakes than no-alewife lakes (Fig. 5c, d; Appendix B). Except for large-cladoceran biomass, which increased between spring and summer in no-alewife lakes, there were no significant changes in biomass from spring to summer in landlocked and no-alewife lakes (Fig. 5; Appendix B). In contrast, the biomass of all groups fell significantly between spring and summer in anadromous lakes (Fig. 5; Appendix B). In spring, zooplankton biomass in anadromous lakes appeared to be higher than that found in no-alewife lakes, but the differences were not significant due to high variability and small sample size (Fig. 5; Appendix B). By summer, largecladoceran and small-copepod biomass in anadromous lakes had declined to the very low levels found in landlocked lakes throughout the year (Fig. 5). For large copepods in anadromous lakes, biomass declined from spring to summer levels that were significantly lower than that found in either landlocked or no-alewife lakes (Fig. 5; Appendix B). For small cladocerans in anadromous lakes, biomass declined from spring to summer levels that were significantly lower than that found in no-alewife lakes (Fig. 5).

Some of the seasonal trends and differences among lake types found in the separate zooplankton groups were also found in the aggregate measure of total crustacean biomass. We found higher total crustacean biomass in no-alewife lakes than in landlocked lakes in the summer, and lower total crustacean biomass in anadromous than in landlocked lakes (Appendix B). There was little difference in total biomass among the lake types in spring, and the only seasonal trend was a significant decrease in total crustacean biomass from spring to summer in anadromous lakes (Appendix B).

Our higher temporal resolution sampling revealed that large-cladoceran biomass was always low in landlocked lakes (near 0 in all lakes on all dates), and always high in our no-alewife lake (Fig. 6a). In anadromous lakes, large-cladoceran biomass was relatively high in April and May, but fell precipitously from late May to mid-June (Fig. 6a). We observed no large cladocerans in either of the anadromous lakes from the end of June through the end of October in 2005. In contrast, we occasionally saw a few large cladocerans (mostly Daphnia catawba) in the landlocked lakes during this same time period. Large-copepod biomass was low in landlocked lakes and higher in the no-alewife lake, although Linsley Pond had a higher spring biomass and lower summer biomass than the typical no-alewife lake (Fig. 6b). The biomass of large copepods in anadromous lakes fell from early June to early July (Fig. 6b), after
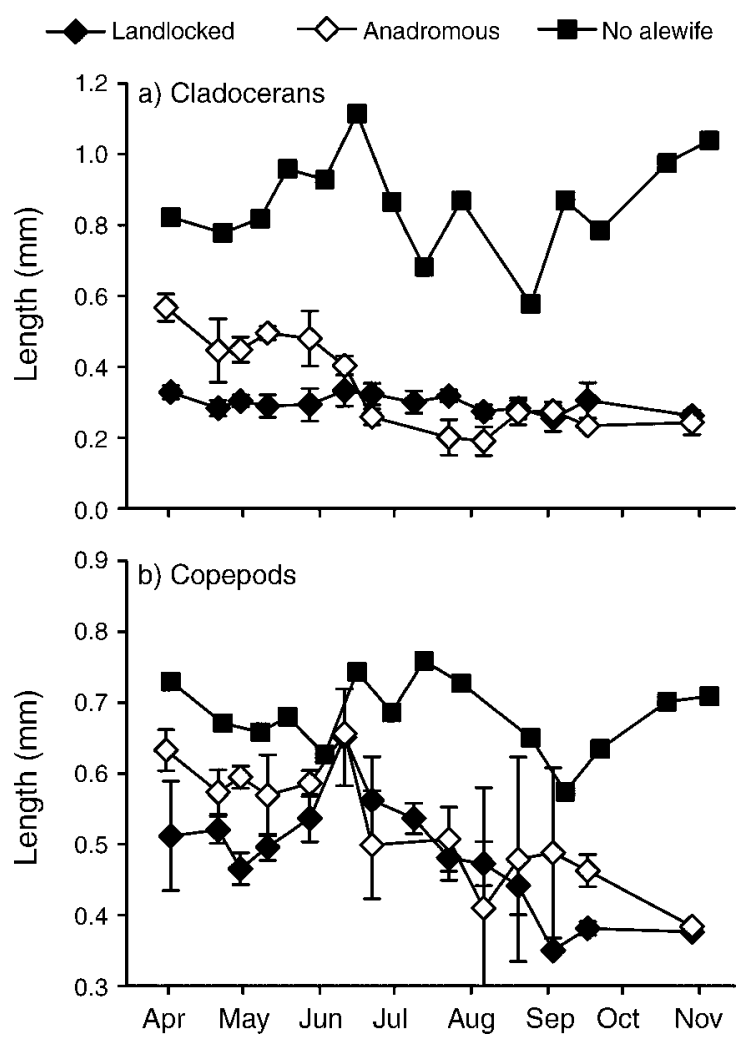

FIG. 4. Mean length $( \pm \mathrm{SE})$ of (a) cladocerans and (b) copepods in landlocked and anadromous lakes and in a noalewife lake from April to November in 2005. The landlocked lakes are Pattagansett, Quonnipaug, and Rogers; the anadromous lakes are Bride and Dodge; the no-alewife lake is Linsley Pond.

which it was low $(1.1 \mu \mathrm{g} / \mathrm{L})$ relative to landlocked lakes $(3.2 \mu \mathrm{g} / \mathrm{L})$ and Linsley Pond $(7 \mu \mathrm{g} / \mathrm{L})$. Small-cladoceran biomass was relatively high in landlocked lakes and quite low in the no-alewife lake throughout the year (Fig. 6c). Once again, small-cladoceran biomass started out very high in anadromous lakes and fell from late May to early July (Fig. 6c). From July to November small-cladoceran biomass in anadromous lakes was similar to that seen in the no-alewife lake (Fig. 6c). In all lakes, small-copepod biomass peaked in early May and declined through to July, after which it remained low (Fig. 6d).

Zooplankton community structure.-In spring, there were significant differences in zooplankton community structure between landlocked and no-alewife lakes (ANOSIM, $R=0.433, P=0.001$ ), and between landlocked and anadromous lakes $(R=0.291, P=$ $0.034)$, but no significant difference between anadromous and no-alewife lakes $(R=0.175, P=0.088$; Appendix C). Seven or eight species groups were required to explain at least $90 \%$ of the difference in spring community composition between pairs of lake types. Bosmina longirostris, Tropocyclops extensus, and Diacyclops thomasi were all more abundant, and 

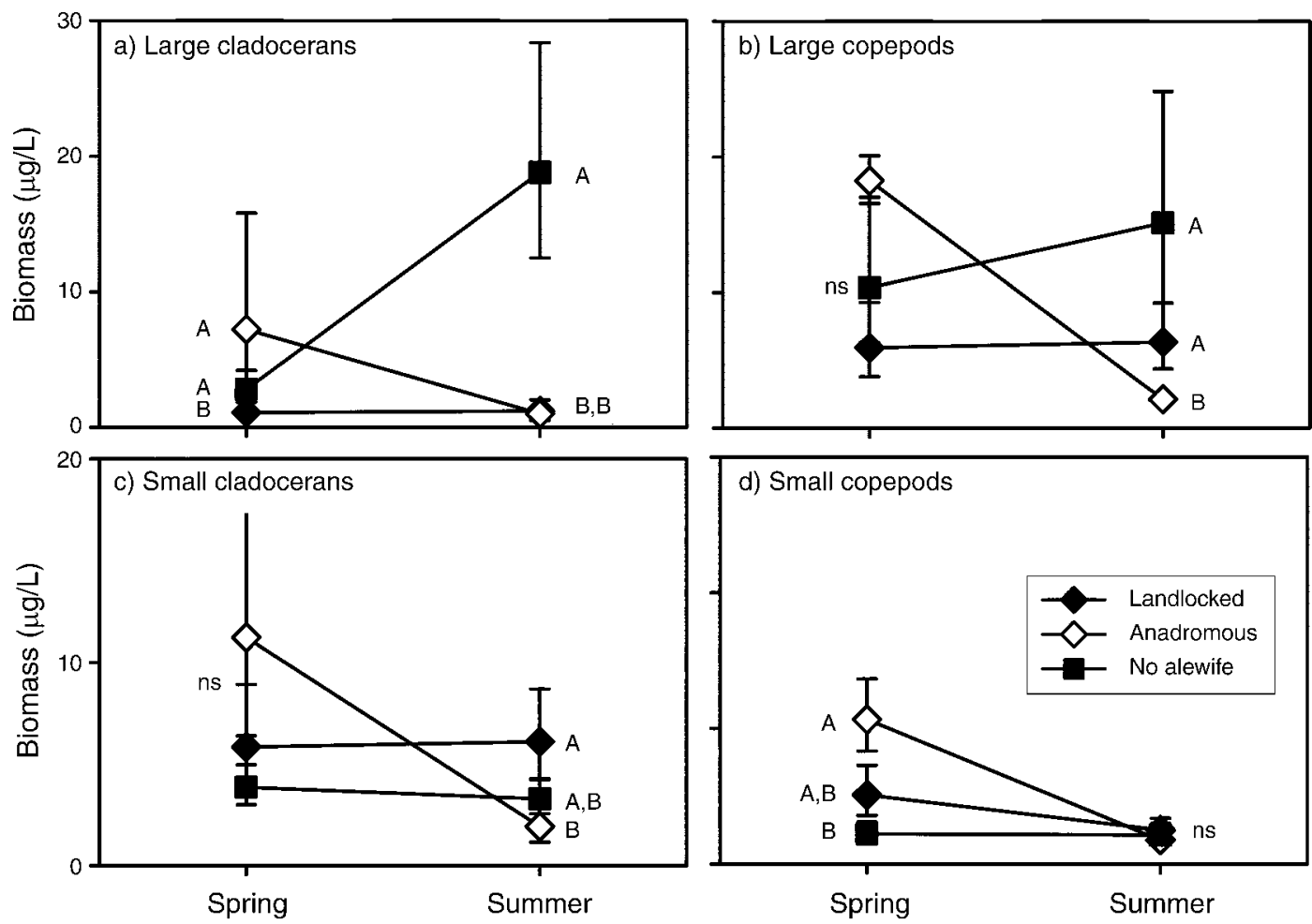

FIG. 5. Mean biomass ( \pm SE) of (a) large cladocerans, (b) large copepods, (c) small cladocerans, and (d) small copepods in landlocked, anadromous, and no-alewife lakes during spring (March and April) and summer (July-September). Note the difference in scale between large (a, b) and small (c, d) zooplankton. Different uppercase letters indicate significant differences $(P \leq 0.05)$ among lake types in spring or summer. Significant differences in biomass between spring and summer were found for anadromous alewife lakes in all cases, and for large cladocerans (a) in no-alewife lakes. All other comparisons between seasons within lake types were not significant (ns).

Diaptomus spp. were less abundant, in anadromous and landlocked alewife lakes than in the no-alewife lakes (Appendix C). Daphnia spp. were more abundant in anadromous and no-alewife lakes than in landlocked lakes, while Mesocyclops edax was most abundant in anadromous lakes (Appendix C). Immature copepods, B. longirostris, T. extensus, and Daphnia spp. explained $67 \%$ of the differences between landlocked and anadromous lakes. Immature copepods, Diaptomus spp., and $B$. longirostris explained $55 \%$ of the differences between landlocked and no-alewife lakes. In general, in spring, the community structures of landlocked and no-alewife lakes were the most dissimilar, with community structure of anadromous lakes roughly intermediate (based on NMDS analysis; Appendix C).

In summer, there were significant differences in zooplankton community structure among all three lake types (ANOSIM, $R=0.208, P=0.035 ; R=0.556, P<$ $0.001 ; R=0.712, P<0.001$ ). Again, seven or eight species groups were required to explain at least $90 \%$ of the difference in summer community composition between pairs of lake types. Daphnia spp., B. longirostris, Diaptomus spp., and immature copepods contributed $84 \%$ of the differences in community structure between no-alewife and anadromous lakes. Those four species plus Cerodaphnia lacustris contributed $81 \%$ of the differences in community structure between anadromous and landlocked lakes. Not surprisingly, largebodied taxa (Daphnia spp., Diaptomus spp., and Mesocyclops edax) were more abundant and smallbodied taxa (B. longirostris, T. extensus, immature copepods) were less abundant in no-alewife lakes than in landlocked or anadromous lakes (Appendix C). Daphnia spp., B. longirostris, immature copepods, $C$. lacustris, and Diaptomus spp. contributed $77 \%$ of the differences in community structure between anadromous and landlocked lakes. Differences in zooplankton community structure between landlocked and anadromous lakes were primarily explained by a higher abundance of the smallest species (B. longirostris, immature copepods) and a lower abundance of the larger species in anadromous lakes when compared to landlocked lakes (Appendix C). The two exceptions were a higher relative abundance of Daphnia spp. in anadromous lakes, perhaps a residual of spring populations (we have never seen Daphnia spp. in anadromous lakes after the end of July), and M. edax, which we collected regularly through the summer in all of the anadromous lakes. Unlike for spring zooplankton communities, the greatest dissimilarity in summer 

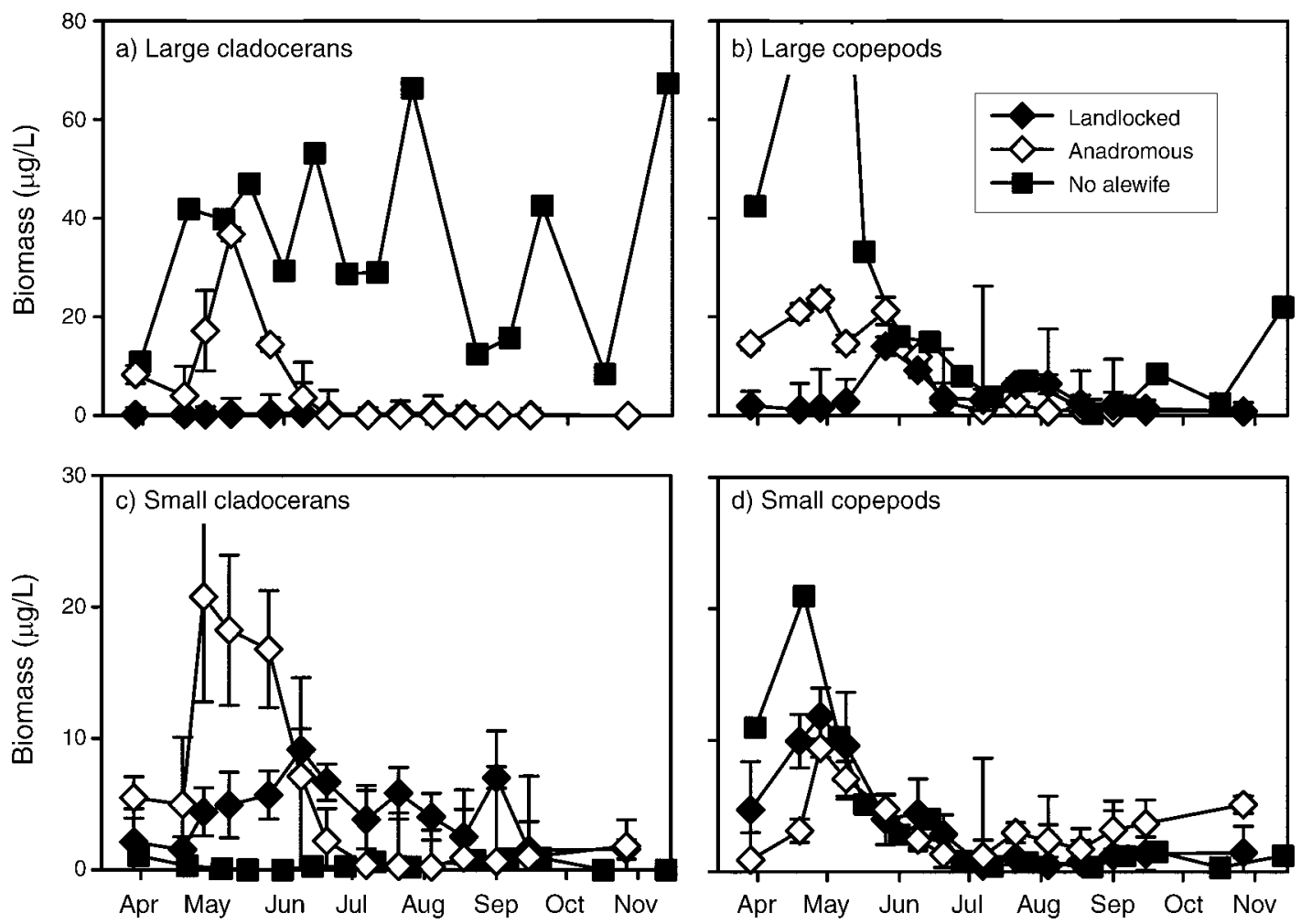

FIG. 6. Mean biomass ( \pm SE) of (a) large cladocerans, (b) large copepods, (c) small cladocerans, and (d) small copepods in landlocked and anadromous lakes and in a no-alewife lake from April to November in 2005. Note the difference in the scale between large (a, b) and small zooplankton (c, d). The landlocked lakes are Pattagansett, Quonnipaug, and Rogers; the anadromous lakes are Bride and Dodge; the no-alewife lake is Linsley Pond.

communities was between no-alewife and anadromous lakes, with landlocked community structure intermediate between those communities (based on NMDS analysis; Appendix C).

Phytoplankton biomass.-Summer total and edible chlorophyll $a$ (chl $a$ ) concentrations, our measures of phytoplankton biomass, were strongly influenced by both spring total phosphorus concentration (TP) and lake type (Fig. 7). For total chl $a$, there was no significant interaction between TP and lake type (ANCOVA, interaction term, $F_{2,19}=0.11, P=0.90$ ), but there were significant main effects of both TP $\left(F_{1,21}\right.$ $=22.1, P<0.01)$ and lake type $\left(F_{2,21}=4.9, P=0.02\right)$. Post hoc tests for differences among lake type indicate that anadromous lakes had significantly higher chl $a$ concentration per unit spring TP than no-alewife lakes (Scheffe's post hoc test, $P=0.02$ ) and marginally higher chl $a$ concentrations than landlocked lakes $(P=0.058$; Fig. 7a). There were no significant differences between landlocked and no-alewife lakes $(P=0.71$; Fig. 7a). For edible chl $a$, there was no significant interaction between TP and lake type (ANCOVA, interaction term, $F_{2,19}=$ $0.42, P=0.67)$, but there were significant main effects of both TP $\left(F_{1,21}=16.8, P<0.01\right)$ and lake type $\left(F_{2,21}=\right.$ 27.0, $P<0.01)$. Edible chl $a$ concentrations per unit spring TP were significantly higher in anadromous than in landlocked (Scheffe's post hoc test, $P<0.01$ ) and noalewife lakes $(P<0.01)$, and significantly higher in landlocked lakes than no-alewife lakes $(P<0.01$; Fig. $7 b)$.

\section{Discussion}

Our results show that both the incidence of alewives and phenotypic differences between landlocked and anadromous alewives strongly affect zooplankton community structure and primary-producer biomass. Landlocked alewives are the archetypal size-selective predator, and their role in regulating zooplankton community structure is well recognized (e.g., Brooks and Dodson 1965). Anadromous alewives also strongly structure zooplankton communities, but they are not ecologically equivalent to landlocked alewives. This demonstrates that intraspecific phenotypic variation in a predator can alter community structure and ecosystem function. In this case, the different ecological roles of anadromous and landlocked alewives derive from differences in the duration of lake residence, foraging morphology, and prey selectivity.

Incidence of alewives. - We found large differences in zooplankton communities between landlocked and noalewife lakes. In landlocked lakes, the zooplankton communities have small mean body size (Figs. 3 and 4), 

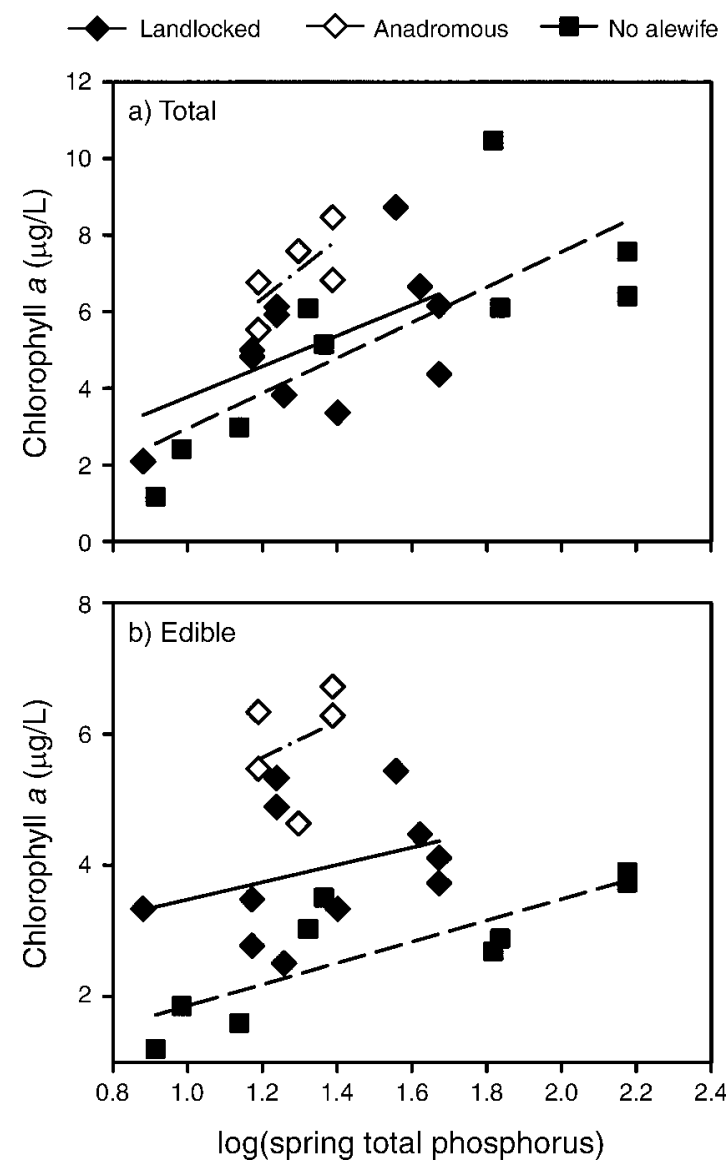

FIG. 7. The relationship between $\log$ (spring total phosphorus concentration), originally measured as $\mu \mathrm{g} / \mathrm{L}$, and summer (a) total and (b) edible $(<30-\mu \mathrm{m})$ chlorophyll $a$ concentrations in landlocked, anadromous, and no-alewife lakes. Each data point represents a different lake, except for the anadromous lakes where we used lake-year data as replicates. "Edible" is the fraction of the phytoplankton community that passed through a $30-\mu \mathrm{g}$ mesh filter, and it is a measure of edible phytoplankton biomass.

low biomass of large copepods and cladocerans, and relatively high biomass of small cladocerans and copepods (Figs. 5 and 6) throughout the growing season. In lakes without alewives, zooplankton communities have a large mean body size (Figs. 3 and 4), high biomass of large copepods and cladocerans, and low biomass of small cladocerans and copepods (Figs. 5 and 6) throughout the growing season. These differences are the same as those found by Brooks and Dodson (1965) and confirm our expectation that the substantial predation pressure exerted by landlocked alewives structures zooplankton communities throughout the year. The seasonally stable differences in zooplankton community structure results from the constant presence or absence of alewives, which results in consistently high or consistently low predation pressure.

Intraspecific differences in the duration of residence.In contrast to landlocked lakes, the spatially open nature of anadromous lakes results in a duration of residence for anadromous alewives of considerably less than one year. Anadromous alewives in our lakes are present from March until the young of the year (YOY) migrate from the lake in late fall (typically October or November); however, YOY are unable to prey upon large zooplankton until June because of gape limitation (Palkovacs 2007). The adult anadromous alewives that are present in March-April typically do not feed before or during spawning and generally leave the lake once they spawn (Loesch 1987). YOY anadromous alewives are present and able to prey upon large zooplankton (gape width $>1.0 \mathrm{~mm}$ ) from mid-June through fall, providing large zooplankton a refuge from predation from December to early June, roughly half the year.

As a result of the seasonal variation in predation intensity, zooplankton community structure in anadromous lakes varies considerably through the year. In spring, anadromous lakes have high mean copepod and cladoceran lengths (although not as high as that found in no-alewife lakes; Fig. 2), and species composition is intermediate between that found in landlocked and noalewife lakes (Appendix C). Interestingly, large-copepod biomass and large- and small-cladoceran biomass are generally higher in the spring in anadromous than in noalewife lakes (Fig. 5). By late June or early July, after anadromous alewives become sufficiently large to take the largest zooplankton (Palkovacs 2007), all cladocerans and most large copepods are eliminated from the water column of anadromous lakes. One exception is Mesocyclops edax, a large-bodied copepod that is not completely eliminated from the water column of anadromous lakes and as a result, remains an important diet item for YOY anadromous alewives through the summer (Palkovacs 2007). The ability of Mesocyclops edax to persist in anadromous lakes may result from its rapid escape response and pronounced diel vertical migration (Williamson 1986). From midsummer through fall, the zooplankton community of anadromous lakes is much more similar to that found in landlocked lakes than in no-alewife lakes. Thus movement of anadromous alewives into and out of spatially open coastal lakes causes considerable seasonal change in the zooplankton community, essentially moving it from a state near that found in no-alewife lakes in the spring to a state more similar to that found in landlocked lakes in the summer.

Differences in summer zooplankton.-The significant differences in zooplankton communities found in landlocked and anadromous lakes in summer indicate that variation in morphology and foraging behavior between anadromous and landlocked alewives is ecologically important. Anadromous alewives, with their larger gape and wider gill raker spacing (Fig. 2, Plate 1; also see Appendix A), tend to prey upon the largest zooplankton in the lake, and predation by anadromous alewives is so intense that we often find no cladocerans in the water column during midsummer (Fig. 6), and the 
biomass of all zooplankton groups can be lower than that found even in landlocked lakes in summer (Fig. 5). This is consistent with estimates of diet selectivity that suggest anadromous alewives seldom miss the opportunity to prey upon the very largest zooplankton in the lake on any given date (Palkovacs 2007). Starting with large zooplankton in June, anadromous alewives sequentially extirpate the largest species from the water column, producing a zooplankton community dominated by the smallest and most predation-resistant species by the end of the summer (immature copepods, small calanoid copepods, and interestingly, Mesocyclops edax). In contrast, landlocked alewives tend to prey upon the most common zooplankton in the lake (Palkovacs 2007), and as a result we occasionally find large and always find small cladocerans in the water column of landlocked lakes (Fig. 6). Predation by landlocked alewives appears to select the most abundant species (typically Bosmina spp. and small calanoid copepods), which relaxes predation pressure on intermediate-sized copepods and cladocerans (e.g., Cerodaphnia spp., Diaphanosoma spp., and Diaptomus spp.) and leads to the larger mean size of copepods and cladocerans found in landlocked lakes when compared to anadromous lakes (Fig. 3). While landlocked alewives can take larger zooplankton when they are available (Brooks and Dodson 1965), landlocked alewives are neutrally size selective in landlocked lakes where large zooplankton are rare (Palkovacs 2007).

Differences in zooplankton biomass, length, and community composition could also result from differences in the biomass of alewives in anadromous and landlocked lakes. We found no significant difference in the biomass of anadromous and landlocked populations in six of our study lakes (Fig. 2); however, it is possible these six lakes differ from the broader population of lakes we sampled. Using data collected in 2005 in these six lakes (Bride, Dodge, Gorton, Pattagansett, Quonnipaug, and Rogers), we tested the effect of lake type and alewife biomass (July-August) on mean summer cladoceran length and large-copepod biomass, the two variables that were significantly different in summer between anadromous and landlocked lakes (Fig. 8). For cladoceran length, we found a significant effect of lake type $\left(F_{1,2}=58.9, P=0.02\right)$, a marginally significant effect of alewife biomass $\left(F_{1,2}=11.3, P=0.08\right)$, and a marginally significant interaction between lake type and alewife biomass $\left(F_{1,2}=15.0, P=0.06\right)$. For largecopepod biomass, we found a significant effect of lake type $\left(F_{1,2}=230.8, P<0.01\right)$, no significant effect of alewife biomass $\left(F_{1,2}=0.08, P=0.81\right)$, and a significant interaction between lake type and alewife biomass $\left(F_{1,2}\right.$ $=50.2, P=0.02$ ). In both cases, alewife phenotype (as indicated by lake type) had a much stronger effect on the zooplankton community than alewife biomass (Fig. 8). Biomass had a negative effect on cladoceran length and large-copepod biomass in landlocked lakes, but no effect on cladoceran length and a positive effect on large-
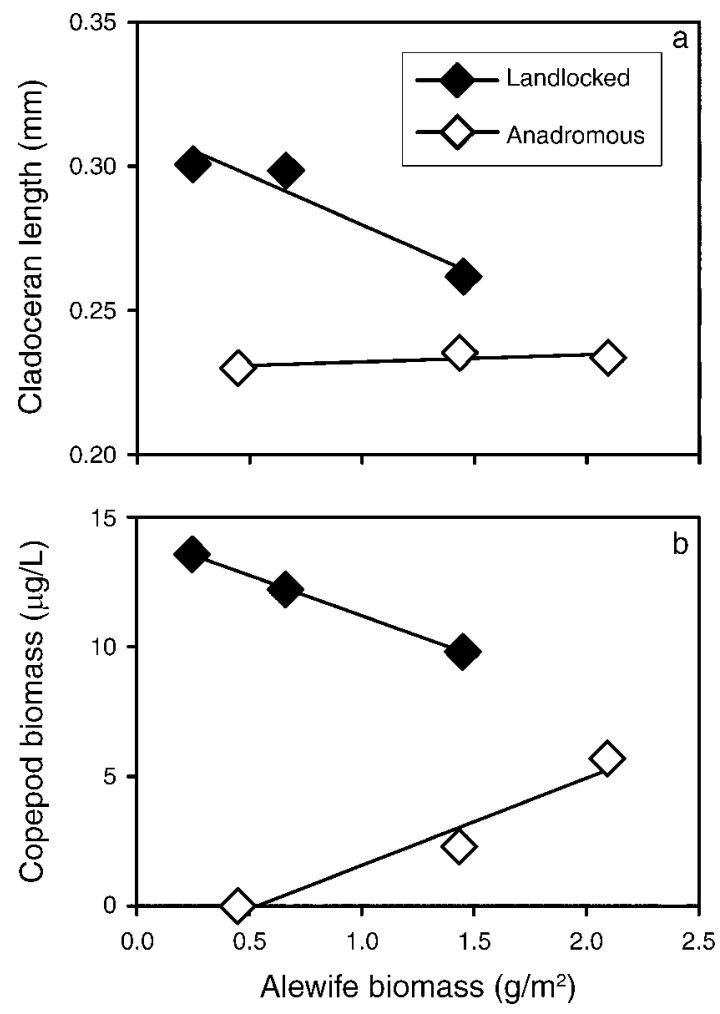

FIG. 8. The relationships (a) between cladoceran length and alewife biomass and (b) between copepod biomass and alewife biomass in three anadromous lakes (Bride, Dodge, and Gorton) and three landlocked lakes (Pattagansett, Quonnipaug, and Rogers) in the summer of 2005.

copepod biomass in anadromous lakes (Fig. 8). Cladoceran length and copepod biomass were both higher in landlocked than anadromous lakes, regardless of alewife biomass, clearly demonstrating the strong effect of alewife phenotype on zooplankton communities (Fig. 8). The persistent effect of alewife phenotype on zooplankton community structure is consistent with results from a common garden mesocosm experiment that demonstrated that alewife phenotype affects zooplankton length, biomass, and community structure independent of alewife biomass (E. Palkovacs and D. Post, unpublished manuscript).

Cascading trophic interaction.-Intraspecific phenotypic differences strongly influenced the strength of the trophic cascade caused by alewives (Fig. 7). Anadromous alewives caused a much greater increase in edible phytoplankton biomass per unit of spring total phosphorus than did landlocked alewives, and only anadromous alewives caused significant changes in total phytoplankton biomass (Fig. 7). The higher biomass of phytoplankton is consistent with the smaller mean size and lower mean biomass of zooplankton (particularly herbivorous cladocerans) found in anadromous lakes. The stronger effect of alewives on edible than on total phytoplankton biomass is also consistent with observations that small phytoplankton are more sensi- 

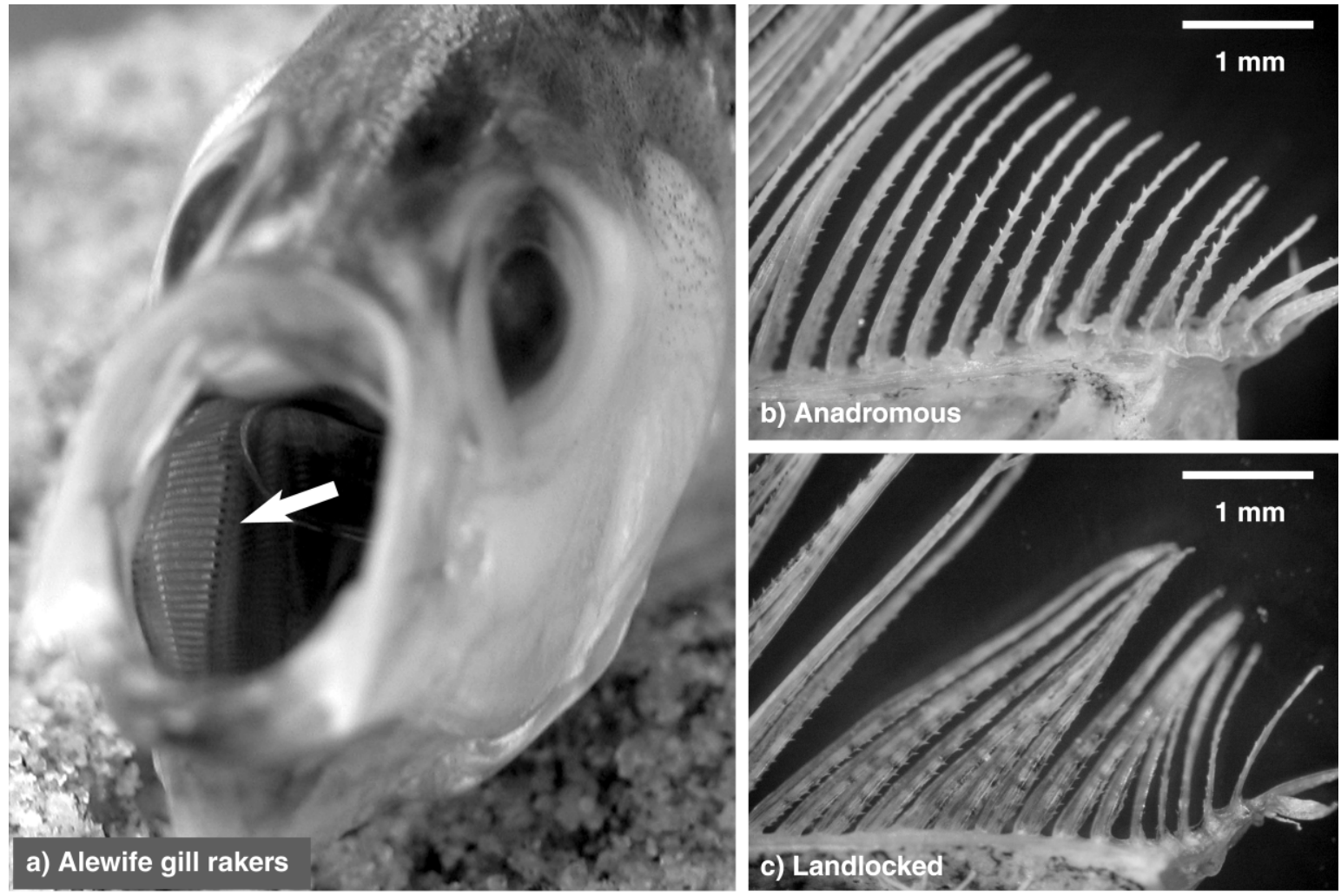

Plate 1. (a) The gill rakers of an alewife. The two right-handed panels show the upper gill arch from (b) an anadromous alewife (Bride Lake, total length $=97 \mathrm{~mm}$ ) and $(\mathrm{c})$ a landlocked alewife (Rogers Lake, total length $=99 \mathrm{~mm}$ ). Note difference in gill raker spacing (anadromous > landlocked). Photo credits: D. Post, panel (a); E. Palkovacs, panels (b) and (c).

tive to changes in grazing pressure than large phytoplankton (Carpenter and Kitchell 1993, Carpenter et al. 1996, Post et al. 1997). We have not yet evaluated the relative importance of changes in nutrient cycling and changes in grazing pressure (e.g., Vanni and Layne 1997), nor have we fully disentangled the effects of alewife morphology and biomass on grazer size and biomass, but it is clear that anadromous alewives cause stronger trophic cascades during the summer than landlocked alewives (Fig. 7).

Conclusion.-Our results show that landlocked and anadromous alewives are not ecologically equivalent. As such, intraspecific variation in this keystone species is essential for understanding community structure and cascading trophic interactions among coastal lakes in New England. Differences in the duration of residence, foraging morphology, and zooplankton prey selectivity interact to produce striking differences in zooplankton community structure and algal biomass between lakes with anadromous or landlocked alewives. Our results complement recent work on dominant plant species (Treseder and Vitousek 2001, Proffitt et al. 2005, Wimp et al. 2005, Whitham et al. 2006) by demonstrating that phenotypic variation in predators can have strong effects on community structure and ecosystem function. Our results also represent an important step toward linking the reciprocal feedbacks between ecology and evolution that are implicit in the process of evolution (Thompson 1998, Yoshida et al. 2003, Hairston et al. 2005, Palkovacs 2007). Here phenotypic differences strongly influence prey community structure, which we believe has in turn influenced phenotypic divergence. Our results highlight the importance of studying the effects of intraspecific variation on community structure and ecosystem processes. Ecologists and evolutionary biologists should more thoroughly explore the origin and consequences of intraspecific variation, particularly in species that regulate community structure and ecosystem function, because of its potential to strongly alter ecological interactions and the ecological context in which evolution occurs.

\section{ACKNOWLEDGMENTS}

We thank C. Dalton, R. Doud, B. Kochin, C. Winkworth, and T. Ratliff for help in the field and lab. L. Puth, O. Schmitz, and S. Stearns provided helpful comments and advice. This research was supported by the Connecticut Institute of Water Resources, an EPA STAR Graduate Fellowship Award to E. P. Palkovacs, and the National Science Foundation (DEB No. 0717265).

\section{Literature Cited}

Abrams, P. A., and H. Matsuda. 1997. Prey adaptation as a cause of predator-prey cycles. Evolution 51:1742-1750. 
Atlantic States Marine Fisheries Commission (ASMFC). 1999. Amendment 1 to the Interstate Fishery Management Plan for Shad \& River Herring. ASMFC Fishery Management Report Number 35, Hanover, New Hampshire, USA.

Bell, M. A., and S. A. Foster. 1994. The evolutionary biology of the threespine stickleback. Oxford University Press, Oxford, UK.

Brooks, J. L., and S. I. Dodson. 1965. Predation, body size, and the composition of plankton. Science 150:28-35.

Carpenter, S. R., J. J. Cole, J. R. Hodgson, J. F. Kitchell, M. L. Pace, D. Bade, K. L. Cottingham, T. E. Essington, J. N. Houser, and D. E. Schindler. 2001. Trophic cascades, nutrients, and lake productivity: whole-lake experiments. Ecological Monographs 71:163-186.

Carpenter, S. R., and J. F. Kitchell, editors. 1993. The trophic cascade in lakes. Cambridge University Press, Cambridge, UK.

Carpenter, S. R., J. F. Kitchell, K. L. Cottingham, D. E. Schindler, D. L. Christensen, D. M. Post, and N. Voichick. 1996. Chlorophyll variability, nutrient input and grazing: evidence from whole-lake experiments. Ecology 77:725-735.

Carpenter, S. R., J. F. Kitchell, J. R. Hodgson, P. A. Cochran, J. J. Elser, M. M. Elser, D. M. Lodge, D. Kretchmer, X. He, and C. N. von Ende. 1987. Regulation of lake primary productivity by food web structure. Ecology 68:1863-1876.

Clarke, K. R. 1993. Non-parametric multivariate analyses of changes in community structure. Australian Journal of Ecology 18:117-143.

Day, T., J. Pritchard, and D. Schluter. 1994. Ecology and genetics of phenotypic plasticity: a comparison of two sticklebacks. Evolution 48:1723-1734.

Dieckmann, U., and M. Doebeli. 1999. On the origin of species by sympatric speciation. Nature 400:354-357.

Doebeli, M., and U. Dieckmann. 2003. Speciation along environmental gradients. Nature 421:259-264.

Downing, J. A., and F. H. Rigler. 1984. A manual on methods for the assessment of secondary productivity in fresh waters. Blackwell Scientific Publications, Oxford, UK.

Eck, G. W., and L. Wells. 1987. Recent changes in Lake Michigan's fish community and their probable causes, with emphasis on the role of the alewife (Alosa pseudoharengus). Canadian Journal of Fisheries and Aquatic Sciences 44:5360.

Estes, J. A., and J. F. Palmisan. 1974. Sea otters: their role in structuring nearshore communities. Science 185:1058-1060.

Foote, C. J., K. Moore, K. Stenberg, K. J. Craig, J. K. Wenburg, and C. C. Wood. 1999. Genetic differentiation in gill raker number and length in sympatric anadromous and nonanadromous morphs of sockeye salmon, Oncorhynchus nerka. Environmental Biology of Fishes 54:263-274.

Frink, C. R., and W. A. Norvell. 1984. Chemical and physical properties of Connecticut lakes. Bulletin 817. The Connecticut Agricultural Experimental Station, New Haven, Connecticut, USA.

Funk, W. C., J. A. Tyburczy, K. L. Knudsen, K. R. Lindner, and F. W. Allendorf. 2005. Genetic basis of variation in morphological and life-history traits of a wild population of pink salmon. Journal of Heredity 96:24-31.

Graeb, B. D. S., T. Galarowicz, D. H. Wahl, J. M. Dettmers, and M. J. Simpson. 2005. Foraging behavior, morphology, and life history variation determine the ontogeny of piscivory in two closely related predators. Canadian Journal of Fisheries and Aquatic Sciences 62:2010-2020.

Graham, J. J. 1956. Observations on the alewife, Pomolobus pseudoharengus (Wilson), in fresh water. University of Toronto Biological Series Number 62, Publications of the Ontario Fisheries Research Laboratory 74.

Gregory, R. S., G. S. Brown, and G. R. Daborn. 1983. Food habits of young anadromous alewives, Alosa pseudoharengus, in Lake Ainslie, Nova Scotia. Canadian Field-Naturalist 97: 423-426.
Hairston, N. G., S. P. Ellner, M. A. Geber, T. Yoshida, and J. A. Fox. 2005. Rapid evolution and the convergence of ecological and evolutionary time. Ecology Letters 8:11141127.

Hairston, N. G., Sr., F. E. Smith, and L. B. Slobodkin. 1960. Community structure, population control, and competition. American Naturalist 94:421-425.

Harman, W. N., and M. F. Albright. 2002. Trophic changes in Otsego Lake, NY following the introduction of the alewife (Alosa pseudoharengus). Lake and Reservoir Management 18: 215-226.

Hendry, A. P., T. Bohlin, B. Jonsson, and O. K. Berg. 2004. To sea or not to sea? Anadromy versus non-anadromy in Salmonids. Oxford University Press, Oxford, UK.

Jacobs, R. P., and E. B. O'Donnell. 2002. A fisheries guide to lakes and ponds of Connecticut. Connecticut Department of Environmental Protection, Hartford, Connecticut, USA.

Johnson, M. T. J., and A. A. Agrawal. 2005. Plant genotype and environment interact to shape a diverse arthropod community on evening primrose (Oenothera biennis). Ecology 86:874-885.

Jones, C. G., J. H. Lawton, and M. Shachak. 1994. Organisms as ecosystem engineers. Oikos 69:373-386.

Lazzaro, X. 1987. A review of planktivorous fishes: their evolution, feeding behaviours, selectivities, and impacts. Hydrobiologia 146:97-167.

Loesch, J. G. 1987. Overview of life history aspects of anadromous alewife and blueback herring in freshwater habitats. American Fisheries Society Symposium 1:89-103.

Macneill, D. B., and S. B. Brandt. 1990. Ontogenic shifts in gillraker morphology and predicted prey capture efficiency of the alewife, Alosa pseudoharengus. Copeia 1980:164-171.

Madenjian, C. P., et al. 2002. Dynamics of the Lake Michigan food web, 1970-2000. Canadian Journal of Fisheries and Aquatic Sciences 59:736-753.

Marker, A. F. H., C. A. Crowther, and R. J. M. Gunn. 1980. Methanol and acetone as solvents for estimating chlorophyll $a$ and phaeopigments by spectrophotometry. Archiv für Hydrobiologie, Ergebnisse der Limnologie 14:52-69.

McDowall, R. M. 1988. Diadromy in fishes. Timber Press, Portland, Oregon, USA.

Menge, B. A., E. L. Berlow, C. A. Blanchette, S. A. Navarrete, and S. B. Yamada. 1994. The keystone species concept: variation in interaction strength in a rocky intertidal habitat. Ecological Monographs 64:249-286.

Mills, E. L., et al. 2003. Lake Ontario: food web dynamics in a changing ecosystem (1970-2000). Canadian Journal of Fisheries and Aquatic Sciences 60:471-490.

Mummert, J. R., and R. W. Drenner. 1986. Effect of fish size on the filtering efficiency and selective particle ingestion of a filter-feeding clupeid. Transactions of the American Fisheries Society 115:522-528.

Nursall, J. R. 1974. Character displacement and fish behavior, especially in coral-reef communities. American Zoologist 14: 1099-1118.

Oksanen, L., S. D. Fretwell, J. Arruda, and P. Niemelä. 1981. Exploitation ecosystems in gradients of primary productivity. American Naturalist 118:240-261.

Pace, M. L., J. J. Cole, S. R. Carpenter, and J. F. Kitchell. 1999. Trophic cascades revealed in diverse ecosystems. Trends in Ecology and Evolution 14:483-488.

Paine, R. T. 1966. Food web complexity and species diversity. American Naturalist 100:65-75.

Palkovacs, E. P. 2007. Feedbacks between ecology and evolution: linking the causes and consequences of functional biodiversity. Dissertation. Yale University, New Haven, Connecticut, USA.

Palkovacs, E. P., K. B. Dion, D. M. Post, and A. Caccone. 2008. Independent evolutionary origin of landlocked alewife populations and rapid parallel evolution of phenotypic traits. Molecular Ecology 17:582-597. 
Phillips, C., E. Schluntz, and J. Bender. 1987. Landlocked alewife (Alosa pseudoharengus) research and management in Connecticut lakes and ponds. Connecticut Department of Environmental Protection, Hartford, Connecticut, USA.

Post, D. M., S. R. Carpenter, D. L. Christensen, K. L. Cottingham, J. R. Hodgson, J. F. Kitchell, and D. E. Schindler. 1997. Seasonal effects of variable recruitment of a dominant piscivore on pelagic food web structure. Limnology and Oceanography 42:722-729.

Post, D. M., and J. F. Kitchell. 1997. Trophic ontogeny and life history effects on interactions between age-0 fishes and zooplankton. Archiv für Hydrobiologie, Advances in Limnology 49:1-12.

Power, M. E., D. Tilman, J. A. Estes, B. A. Menge, W. J. Bond, L. S. Mills, G. Daily, J. C. Castilla, J. Lubchenco, and R. T. Paine. 1996. Challenges in the quest for keystones: identifying keystone species is difficult-but essential to understanding how loss of species will affect ecosystems. Bioscience 46:609620.

Proffitt, C. E., R. L. Chiasson, A. B. Owens, K. R. Edwards, and S. E. Travis. 2005. Spartina alterniflora genotype influences facilitation and suppression of high marsh species colonizing an early successional salt marsh. Journal of Ecology 93:404-416.

Reznick, D., M. J. Butler, and H. Rodd. 2001. Life-history evolution in guppies. VII. The comparative ecology of high- and low-predation environments. American Naturalist 157:126140.

Reznick, D. N., and C. K. Ghalambor. 2001. The population ecology of contemporary adaptations: what empirical studies reveal about the conditions that promote adaptive evolution. Genetica 112:183-198.

Reznick, D. N., F. H. Shaw, F. H. Rodd, and R. G. Shaw. 1997. Evaluation of the rate of evolution in natural populations of guppies (Poecilia reticulata). Science 275: 1934-1937.

Rundle, H. D., and P. Nosil. 2005. Ecological speciation. Ecology Letters 8:336-352.

Schluter, D. 2001. Ecology and the origin of species. Trends in Ecology and Evolution 16:372-380.

Schluter, D., and J. D. McPhail. 1992. Ecological character displacement and speciation in sticklebacks. American Naturalist 140:85-108.

Schmitz, O. J., P. A. Hamback, and A. P. Beckerman. 2000. Trophic cascades in terrestrial systems: a review of the effects of carnivore removals on plants. American Naturalist 155: 141-153.

Schmitz, O. J., and K. B. Suttle. 2001. Effects of top predator species on direct and indirect interactions in a food web. Ecology 82:2072-2081.

Scott, W. B., and E. J. Crossman. 1973. Freshwater fishes of Canada. Bulletin of the Fisheries Research Board of Canada. Number 184. Fisheries Research Board of Canada, Ottawa, Ontario, Canada.

Sokal, R. R., and F. J. Rohlf. 1995. Biometry. Third edition. W. H. Freeman, New York, New York, USA.

Thompson, J. N. 1988. Variation in interspecific interactions. Annual Review of Ecology and Systematics 19:65-87.

Thompson, J. N. 1998. Rapid evolution as an ecological process. Trends in Ecology and Evolution 13:329-332.

Treseder, K. K., and P. M. Vitousek. 2001. Potential ecosystem-level effects of genetic variation among populations of Metrosideros polymorpha from a soil fertility gradient in Hawaii. Oecologia 126:266-275.

Vanni, M. J., and C. D. Layne. 1997. Nutrient recycling and herbivory as mechanisms in the "top-down" effect of fish on algae in lakes. Ecology 78:21-40.

Vigerstad, T. J., and J. S. Cobb. 1978. Effects of predation by sea-run juvenile alewives (Alosa pseudoharengus) on the zooplankton community at Hamilton Reservoir, Rhode Island. Estuaries 1:36-45.

Wells, L. 1970. Effects of alewife predation on zooplankton populations in Lake Michigan. Limnology and Oceanography 15:556-565.

Whitham, T. G., et al. 2006. A framework for community and ecosystem genetics: from genes to ecosystems. Nature Reviews Genetics 7:510-523.

Williamson, C. E. 1986. The swimming and feeding-behavior of Mesocyclops. Hydrobiologia 134:11-19.

Wimp, G. M., G. D. Martinsen, K. D. Floate, R. K. Bangert, and T. G. Whitham. 2005. Plant genetic determinants of arthropod community structure and diversity. Evolution 59:61-69.

Wimp, G. M., W. P. Young, S. A. Woolbright, G. D. Martinsen, P. Keim, and T. G. Whitham. 2004. Conserving plant genetic diversity for dependent animal communities. Ecology Letters 7:776-780.

Yoshida, T., L. E. Jones, S. P. Ellner, G. F. Fussmann, and N. G. Hairston. 2003. Rapid evolution drives ecological dynamics in a predator-prey system. Nature 424:303-306.

\section{APPENDIX A}

The morphology of anadromous and landlocked alewife populations (Ecological Archives E089-117-A1).

\section{APPENDIX B}

Results of the planned contrasts for zooplankton length and biomass (Ecological Archives E089-117-A2).

\section{APPENDIX C}

Nonmetric multidimensional scaling (NMDS) plots and the relative contribution of species to overall community differences (Ecological Archives E089-117-A3). 